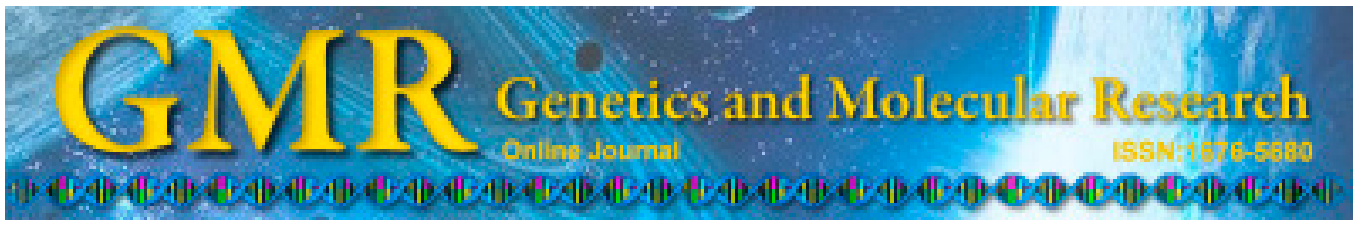

\title{
Cloning and expression of the porcine attaching and effacing-associated (paa) gene of enteropathogenic Escherichia coli
}

\author{
D.A. Pereira ${ }^{3}$, E.C. Teixeira Florian ${ }^{1}$, M.A. Ono ${ }^{2}$, C. Nachi Rossi ${ }^{1}$, \\ O. Vidotto ${ }^{1}$ and M.C. Vidotto ${ }^{1}$ \\ ${ }^{1}$ Laboratório de Protozoologia Veterinária, \\ Departamento de Medicina Veterinária Preventiva, \\ Universidade Estadual de Londrina, Londrina, PR, Brasil \\ ${ }^{2}$ Laboratório de Imunologia Animal, Departamento de Ciências Patológicas, \\ Universidade Estadual de Londrina, Londrina, PR, Brasil \\ ${ }^{3}$ Programa de Pós Graduação em Ciência Animal, \\ Universidade Estadual de Londrina, Londrina, PR, Brasil
}

Corresponding author: M.C. Vidotto

E-mail: macarlos@uel.br

Genet. Mol. Res. 14 (3): 8574-8580 (2015)

Received August 8, 2014

Accepted April 24, 2015

Published July 31, 2015

DOI http://dx.doi.org/10.4238/2015.July.31.5

\begin{abstract}
Porcine enteropathogenic Escherichia coli (PEPEC) produce an outer membrane protein (intimin) called Paa (porcine attaching and effacing-associated), which is involved in the pathogenesis of E. coli in piglets with diarrhea. The paa gene of a PEPEC strain isolated in Paraná, Brazil, was amplified by polymerase chain reaction, sequenced, and cloned into the pTrcHisTOPO2 vector. The deduced amino acid sequence encoded by the paa gene of PEPEC from Paraná, Brazil, showed 99\% homology to the sequences from other PEPEC strains. In this study, the overexpression of recombinant Paa (rPaa) using alternative induction strategies was attempted. The auto-induction protocol showed excellent results for $\mathrm{rPaa}$ protein production with $0.4 \%$ $(\mathrm{w} / \mathrm{v})$ lactose. The rPaa protein is insoluble and was purified with Triton
\end{abstract}


$\mathrm{X}-100$ wash as a total antigen. This method produced a relatively high yield of rPaa. rPaa was recognized by serum from pigs immunized with the PEPEC strain. These results suggest that $\mathrm{rPa}$ could be included in the development of a vaccine against swine colibacillosis.

Key words: Porcine enteropathogenic Escherichia coli; paa gene; Post-weaning diarrhea; Piglets; Colibacillosis

\section{INTRODUCTION}

Non-enterotoxigenic Escherichia coli strains have been associated with post-weaning diarrhea and neonatal diarrhea in swine, through adhesion to intestinal epithelial cells in a characteristic attaching and effacing (A/E) pattern (Batisson et al., 2003). Porcine enteropathogenic E. coli (PEPEC) produces an outer membrane protein (intimin), which is involved in the intimate attachment of the bacteria to enterocytes and induces typical $\mathrm{A} / \mathrm{E}$ lesions, as observed in a pig ileal explant model (Zhu et al., 1994, 1995). These A/E lesions contribute to the initial phases of PEPEC pathogenicity (Batisson et al., 2003).

The gene in PEPEC that induces the A/E lesions has been designated paa (porcine attaching and effacing-associated) (An et al., 1999). Its sequence revealed an open reading frame of $753 \mathrm{bp}$ encoding a 27.6-kDa protein, which displayed significant similarities with the Paa of enterohemorrhagic E. coli (EHEC) O157:H7 strains (Batisson et al., 2003).

The paa gene is also associated with other virulence genes of enterotoxigenic E. coli (ETEC); its conservation and expression have been shown in the O149 ETEC collection, and all paa-positive strains possess ETEC virulence genes. paa is mostly found with the enterotoxin gene estA and the autotransporter gene sepA, and it is carried on high-molecular weight plasmids (Leclerc et al., 2007). In Brazil, the paa gene has also been found in association with genes for other adhesins and toxins, and it has been found in $22 \%$ of $E$. coli strains isolated from piglets (Vidotto et al., 2013).

$\mathrm{A} / \mathrm{E}$ lesions have been experimentally reproduced in newborn piglets, and both Paa and Tir proteins of PEPEC have been confirmed to be involved in A/E lesions in vivo (Girard et al., 2005). Considering that the Paa protein is important in virulence and that a mutant strain, PEPEC O45 (deltaler), which does not have toxins but expresses the paa gene, could be used as an attenuated vaccine candidate against PEPEC O45 (Hu et al., 2009), we cloned and expressed the paa gene to produce the recombinant $\mathrm{Paa}(\mathrm{rPaa})$ protein in the development of a vaccine against swine colibacillosis.

\section{MATERIAL AND METHODS}

\section{Strains, vectors, and chemicals}

The paa-positive E. coli strain PEPEC was isolated from piglets with diarrhea in Paraná State (Vidotto et al., 2009, 2013). E. coli TOP 10 and E. coli host strain BL21 (DE3) purchased from the Invitrogen Corporation (San Diego, CA, USA) were used to produce a Paa recombinant protein. Vector pTrcHisTOPO2 (Invitrogen, Carlsbad, CA, USA) was used for cloning and expression studies. All chemical reagents were obtained from Sigma Chemical Co. (St. Louis, MO, USA). 


\section{Cloning and sequence analysis of the paa gene from PEPEC}

The paa gene was amplified from paa-positive PEPEC genomic DNA by polymerase chain reaction (PCR). The base sequences for the specific oligonucleotide primers used in this study were based on PAA PEPEC O45, forward: 5'-TCTTCTGCTGCTTATGCTGATATC3', and PAA PEPEC O45, reverse: 5'- TTACCAGCCATATTTTTTGAATGC-3', annealing at nucleotides 37 to 60 and 718 to 738 of the paa gene, respectively (Vidotto et al., 2013).

PCR was carried out in a total volume of $25 \mu \mathrm{L}$, containing $5 \mu \mathrm{L}$ template DNA, 20 pmol of each of the primers, $200 \mu \mathrm{M}$ dNTPs, 1 X PCR buffer, and 1.5 U Taq DNA polymerase (Invitrogen Life Technologies, São Paulo, Brazil). The PCR conditions were as follows: $94^{\circ} \mathrm{C}$ for $5 \mathrm{~min}$, followed by 30 cycles at $94^{\circ} \mathrm{C}$ for $1 \mathrm{~min}$, annealing at $55^{\circ} \mathrm{C}$ for $1 \mathrm{~min}$ and $72^{\circ} \mathrm{C}$ for $1 \mathrm{~min}$, followed by a final extension at $72^{\circ} \mathrm{C}$ for $7 \mathrm{~min}$ in a thermal cycler (Biocycler). The amplified DNA was visualized on a $1.5 \%$ agarose gel stained with SYBR Safe (Invitrogen). A 100-bp ladder (Promega, Madison, WI, USA) was used as a standard for determining the molecular mass of the PCR products.

The PCR products were quantified and used as inserts in the pTrcHisTOPO2 vector (Invitrogen, Carlsbad, CA, USA) according to manufacturer instructions. Chemically competent $E$. coli host strain TOP10 cells were then transformed with $3 \mu \mathrm{L}$ of the cloning reaction product. The transformant colonies were selected on plates containing $50 \mu \mathrm{g} / \mathrm{mL}$ ampicillin, and the presence of the paa gene was confirmed by PCR. The recombinant plasmids were extracted using a QIAprep Spin Miniprep Kit (Qiagen Inc.), and the correct position of the paa gene was confirmed by sequencing with primers $\mathrm{pTrcHis}$ forward and paa reverse, utilizing a BigDye Terminator commercial kit (Applied Biosystems, CA, USA). The sequences obtained were analyzed using BLASTN accessed through the NCBI website (http://www.ncbi.nlm.nih. gov/) to verify the sequence identity. DNA and amino acid sequence analyses were carried out using the CAP3 Contig Assembly Program, Clustal W (1.81) Multiple Sequence Alignments, and Six Frame Translation of Sequence software.

\section{Expression of the paa gene in an $E$. coli strain}

\section{Conventional isopropyl-1- $\beta$-D-thiogalactopyranoside (IPTG) induction}

E. coli BL21 (DE3) was transformed with the recombinant plasmid $\mathrm{p}$ TrcHis/paa by thermal shock. The BL21/pTrcHis/paa strain was grown to an optical density at $600 \mathrm{~nm}$ of 0.7 . IPTG (Invitrogen Life Technologies) was then diluted to $1 \mathrm{mM}$, and aliquots were removed at different times to determine the best time for expression. The cells were collected by centrifugation, and expression was determined in soluble and insoluble fractions by $12 \%$ sodium dodecyl sulfate polyacrylamide gel electrophoresis (SDS-PAGE).

\section{Auto-induction}

To overexpress the rPaa, we examined four E. coli BL21 (DE3) strains (RIL, RP, pLysS, and Rosseta) with inducer molecules such as lactose or IPTG. The possibility of using several types of media and lactose as inducers to increase the yields of the recombinant protein was investigated. 
rPaa was overexpressed under auto-induction conditions, as described by Deacon et al. (2008), with slight modifications. Briefly, a seed culture of transformed BL21 (DE3)/ pTrcHis/paa was grown O.N. $\left(37^{\circ} \mathrm{C}\right)$ to saturation in Lysogeny broth medium. Aliquots of $0.1 \mathrm{~mL}$ seed culture were inoculated in Superbroth auto-induction medium (SB auto: tryptone, $32 \mathrm{~g} / \mathrm{L}$; yeast extract, $20 \mathrm{~g} / \mathrm{L})$. The compositions $(\mathrm{g} / \mathrm{L})$ of the supplementary solutions added to the base media were as follows: NPSC stock $\left(\mathrm{Na}_{2} \mathrm{HPO}_{4}, 71 ; \mathrm{KH}_{2} \mathrm{PO}_{4}, 68 ; \mathrm{Na}_{2} \mathrm{SO}_{4}\right.$, $14.2 ; \mathrm{NH}_{4} \mathrm{Cl}, 53.3 ; \mathrm{pH}$ adjusted to 7.0 with $\mathrm{NaOH}$; used at a final concentration of $50 \mathrm{~mL}$ per liter medium); glucose stock (glucose, 25; used at a final concentration of 10-40 mL per liter medium); glycerol stock (glycerol, 250; used at a final concentration of 10-40 mL per liter medium); and lactose stock (lactose, 100; used at final concentration of 10-40 mL per liter medium and grown for $24 \mathrm{~h}$ at $37^{\circ} \mathrm{C}$ with shaking at 250 revolutions per minute). During autoinduction, expression levels were analyzed at 3-h intervals by $15 \%$ SDS-PAGE.

\section{Purification of rPaa}

The culture of induced bacteria was centrifuged, lysed by sonication, and then frozen in liquid nitrogen. This suspension was then centrifuged and the supernatant utilized for protein purification using Ni-nitrilotriacetic acid (NTA) resin columns (Qiagen, Valencia, CA, USA).

The rPaa was also purified as a total antigen; the induced bacteria were collected by centrifugation and incubated in $50 \mathrm{~mL}$ buffer (Tris $0.1 \mathrm{M}, \mathrm{pH} 7.0$; ethylenediaminetetraacetic acid $1 \mathrm{mM}$; lysozyme $1 \mathrm{mg} / \mathrm{mL}$ ) for $1 \mathrm{~h}$ at room temperature. The cells were sonicated on ice with three 5-s pulses at high intensity and then frozen in liquid nitrogen to ensure cell lysis. The rPaa was washed in buffer: Tris $0.1 \mathrm{M}, \mathrm{pH} 8.0, \mathrm{NaCl} 1.5 \mathrm{M}$, ethylenediaminetetraacetic acid $20 \mathrm{Mm}$, and Triton X-100 2\%. The protein content of the purified rPaa was measured using the Bradford method and analyzed by $12 \%$ SDS-PAGE.

\section{SDS-PAGE and western blot}

Lysates were suspended in electrophoresis sample buffer $(0.025 \mathrm{M}$ Tris-HCl, 2\% SDS, $15 \%$ glycerol, $2.5 \%$ 2-mercaptoethanol, $\mathrm{pH} 6.8$ ), boiled for $5 \mathrm{~min}$, and analyzed by $10 \%$ SDS-PAGE. The gels were either stained with Coomassie blue or used for western blots. For western blots, proteins were transferred onto nitrocellulose membranes (Pharmacia Biotech) (Towbin and Gordon, 1984), and the membranes were blocked in blocking buffer [phosphatebuffered saline (PBS) $+0.1 \%$ Tween $20+5 \%$ nonfat dry milk] for $1 \mathrm{~h}$ at room temperature with agitation. The membranes were washed in PBS-T (PBS $+0.1 \%$ Tween 20) and incubated for $1 \mathrm{~h}$ with serum. The proteins were then incubated with anti-pig antibodies conjugated with peroxidase (Sigma Immunochemicals). The membranes were washed and rPaa was detected by incubation with substrate/chromogen solution. Protein molecular mass markers (Rainbow $^{\mathrm{TM}}$ colored, Amersham Life Science) were used as standards.

\section{RESULTS}

paa gene isolation from a positive PEPEC genome was performed by PCR. For the $\mathrm{PCR}$, the primers were designed based on conserved sequences of the paa gene coding region 
from some E. coli strains. Sequences from E. coli O55, PEPEC O45, and ETEC 70463 were aligned using Clustal W (1.81) Multiple Sequence Alignments (data not shown). The forward primer was designed from the 37-bp position, and the reverse primer up to the 738-bp position. After paa open reading frame cloning and sequencing, the sequence was analyzed for similarity to other strains. The analysis of the paa gene coding region from the PEPEC strain indicated that the nucleotides showed high identity (99\%) with the sequence from the other PEPEC strains.

When the amino acid sequence of Paa protein from the Brazilian PEPEC strain was compared with other strains, we observed 91\% similarity with PEPEC 045 (Bruant et al., 2009), $99 \%$ similarity with E. coli 0103 and 055 , and $100 \%$ similarity with E. coli $\mathrm{O} 157: \mathrm{H} 7$ strain EC4115.

The recombined plasmid pTrcHis/paa showed that the paa gene had been inserted at the correct position in the vector. The amount of time that was adequate for the induction of the protein with IPTG was $18 \mathrm{~h}$. The induced Paa protein was recovered from the pellet of the lysed bacteria, as it is insoluble (data not shown).

The auto-induction protocol showed excellent results for $\mathrm{rPaa}$ protein production in simple batch cultivations. E. coli BL21 (DE3)-RP and BL21 Rossetta exhibited the highest quantity with $0.4 \%(\mathrm{w} / \mathrm{v})$ lactose, an induction time of $16-18 \mathrm{~h}$, and an induction temperature of $37^{\circ} \mathrm{C}$ (Figure $1 \mathrm{~A}$, line 2 ).

A)

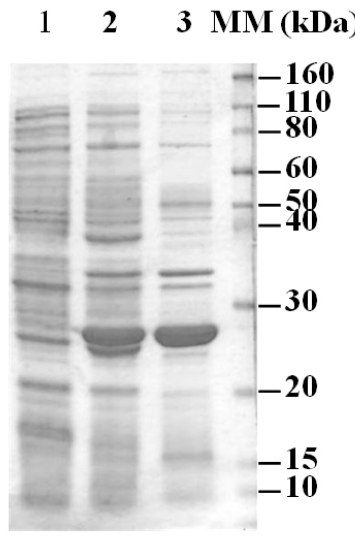

B)

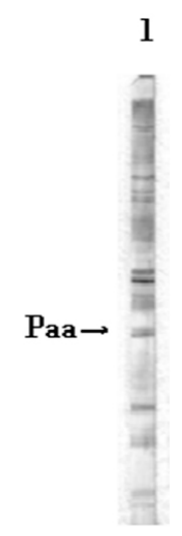

Figure 1. Expression and purification of recombinant Paa (rPaa) protein from clone BL21/pTrcHis/paa. A. 12\% sodium dodecyl sulfate polyacrylamide gel electrophoresis (SDS-PAGE) stained with Coomassie brilliant blue. Lane $M M=$ molecular mass. Lane 1, BL21; lane 2, BL21/pTrcHis/paa induced with $1 \mathrm{mM}$ isopropyl-1- $\beta$-Dthiogalactopyranoside (IPTG); lane 3 = Paa protein. B. Western blotting of rPaa with polyclonal serum produced against the porcine enteropathogenic Escherichia coli (PEPEC) strain.

The rPaa was not purified by the Ni-NTA resin columns method. Because the rPaa protein is insoluble, it was purified with Triton X-100 wash as a total antigen. The SDS-PAGE results showed a 28-kDa rPaa, which was absent in the negative control (Figure 1A line 3). Western blotting analysis showed that the antibody reacted with the induced $28 \mathrm{kDa}$ protein (Figure 1B). 


\section{DISCUSSION}

The association of the paa gene of PEPEC with other ETEC virulence genes suggests its importance in the virulence of PEPEC (Leclerc et al., 2007; Vidotto et al., 2013).

In this study, the sequence of the Paa protein from a Brazilian PEPEC showed 99\% similarity with the Paa protein previously characterized in other strains from different countries. Although there was 91\% similarity with PEPEC 045 (Bruant et al., 2009), the similarity with the E. coli O157:H7 strain EC4115 was 100\%. Trabulsi et al. (2002) also observed that some atypical EPEC strains are genetically closer to the EHEC strains of the O157:H7 serotype than to typical EPEC strains. Similarly, Leclerc et al. (2007) found that the sequence of the Paa protein is highly conserved among ETEC strains and is very similar to that of porcine EPEC and EHEC, suggesting common ancestry and recent dissemination of the gene coding for this virulence factor.

The serogroup O45 is important among PEPEC strains, and based on its virulence gene content, the O45 PEPEC strain is an atypical EPEC locus of enterocyte effacementpositive E. coli lacking the stx 1 and stx 2 genes (Bruant et al., 2009). The PEPEC O45 deletion mutant lost its toxigenicity to Vero cells and was found to be safe for mice and pigs. Oral immunization can induce specific immune responses in mice and pigs, and this mutant strain could be used as an attenuated vaccine candidate against PEPEC O45 (Hu et al., 2009).

The cost and composition of culture media are critical for commercial-scale production of recombinant proteins in E. coli. The rPaa protein was produced with the use of lactose instead of IPTG for induction. Generally, the protein is expressed by recombinant bacteria following induction with IPTG, which is a good inducer and is commonly used in molecular biology. However, it is costly and potentially toxic. Lactose is a natural substrate of the bacterial enzyme that is controlled by the lac operon, which is natively induced. Lactose is a low-cost, harmless, and avirulent compound (Donovan et al., 1996; Deacon et al., 2008).

Additionally, a simple purification process for the recombinant protein is important for commercial-scale production. The rPaa was purified with Triton X-100 wash as total antigen instead of being purified with affinity chromatography in columns loaded with $\mathrm{Ni}^{2+}$. The genetic construct included an N-terminal histidine tag sequence that facilitated recovery, purification, and proper refolding of the vaccine candidate by affinity chromatography; however, this procedure is expensive.

The results suggest that $\mathrm{rPaa}$ could be included in the development of a vaccine against swine colibacillosis.

\section{Conflicts of interest}

The authors declare no conflict of interest.

\section{ACKNOWLEDGMENTS}

Research supported by the Conselho Nacional de Desenvolvimento Científico e Tecnológico (CNPq). 


\section{REFERENCES}

An H, Fairbrother JM, Desautels C and Harel J (1999). Distribution of a novel locus called Paa (porcine attaching and effacing associated) among enteric Escherichia coli. Adv. Exp. Med. Biol. 473: 179-184.

Batisson I, Guimond MP, Girard F, An H, et al. (2003). Characterization of the novel factor paa involved in the early steps of the adhesion mechanism of attaching and effacing Escherichia coli. Infect. Immun. 71: 4516-4525.

Bruant G, Zhang Y, Garneau P, Wong J, et al. (2009). Two distinct groups of porcine enteropathogenic Escherichia coli strains of serogroup $\mathrm{O} 45$ are revealed by comparative genomic hybridization and virulence gene microarray. $B M C$ Genomics 10: 402.

Deacon SE, Roach PC, Postis VL, Wright GS, et al. (2008). Reliable scale-up of membrane protein over-expression by bacterial auto-induction: from microwell plates to pilot scale fermentations. Mol. Membr. Biol. 25: 588-598.

Donovan RS, Robinson CW and Glick BR (1996). Review: optimizing inducer and culture conditions for expression of foreign proteins under the control of the lac promoter. J. Ind. Microbiol. 16: 145-154.

Girard F, Oswald IP, Taranu I, Hélie P, et al. (2005). Host immune status influences the development of attaching and effacing lesions in weaned pigs. Infect. Immun. 73: 5514-5523.

$\mathrm{Hu}$ Y, Song J and Zhao B (2009). Construction and immunization of an attenuated vaccine candidate enteropathogenic Escherichia coli O45. Sheng Wu Gong Cheng Xue Bao_25: 181-188.

Leclerc S, Boerlin P, Gyles C, Dubreuil JD, et al. (2007). paa, originally identified in attaching and effacing Escherichia coli, is also associated with enterotoxigenic E. coli. Res. Microbiol. 158: 97-104.

Towbin H and Gordon J (1984). Immunoblotting and Dot Immunoblotting - current status and outlook. J. Immun. Methods 72: $313-340$

Trabulsi LR, Keller R and Tardelli Gomes TA (2002). Typical and atypical enteropathogenic Escherichia coli. Emerg. Infect. Dis. 8: 508-513.

Vidotto MC, de Lima NC, Fritzen JT, de Freitas JC, et al. (2009). Frequency of virulence genes in Escherichia coli strains isolated from piglets with diarrhea in the North Parana State, Brazil. Braz. J. Microbiol. 40: 199-204.

Vidotto MC, Florian EC and Ono MA (2013). Prevalence of the paa gene (porcine attaching and effacing associated) in porcine enteropathogenic Escherichia coli (PEPEC) associated with postweaning diarrhea in south Brazil. Braz. J. Microbiol. 44: 515-517.

Zhu C, Harel J, Jacques M, Desautels C, et al. (1994). Virulence properties and attaching-effacing activity of Escherichia coli $\mathrm{O} 45$ from swine postweaning diarrhea. Infect. Immun. 62: 4153-4159.

Zhu C, Harel J, Jacques M and Fairbrother JM (1995). Interaction with pig ileal explants of Escherichia coli O45 isolates from swine with postweaning diarrhea. Can. J. Vet. Res. 59: 118-123. 